\title{
From attitudes to behavioral intentions: Stigma and bipolar disorder
}

\author{
Lisa D. Hawke' ${ }^{1}$ Sagar V. Parikh ${ }^{2,3}$ \\ 1. Université de Saint-Boniface, Winnipeg, Canada. 2. University Health Network, Toronto, Canada. 3. University of \\ Toronto, Toronto, Canada.
}

Correspondence: Lisa D. Hawke. Address: Université de Saint-Boniface, Winnipeg, Canada. Email: Ihawke@ustboniface.ca

Received: November 18, 2013

Accepted: December 24, 2013

Online Published: April 8, 2014

DOI : $10.5430 /$ jnep.v4n7p16

URL: http://dx.doi.org/10.5430/jnep.v4n7p16

\section{Abstract}

Background: Bipolar disorder (BD) is a highly stigmatized condition, which has many negative repercussions. Most stigma-reduction interventions aim to reduce stigmatizing attitudes in their target groups. However, attitudinal changes do not necessarily translate into changes in discriminatory behavior. To bridge the gap between attitudes and behaviors, the current study examines the stigmatizing attitudes associated with behavioral intentions, i.e., the willingness to enter into contact with individuals with bipolar disorder.

Methods: A sample of 94 participants completed the Social Distance Scale (SDS) and the Mental Illness Stigma Scale (MISS). Participants were individuals with $\mathrm{BD}$, their friends/family members, healthcare professionals students, and the general public. This study presents baseline data from a research project testing the anti-stigma intervention.

Results: SDS is significantly correlated with four categories of stigmatizing attitudes measured by the MISS: treatability, relationship disruption, hygiene, and anxiety. Greater knowledge about BD is associated with significantly less desire for social distance and more positive attitudes regarding treatability, anxiety and recovery. After controlling for sociodemographic variables and knowledge, only two categories of stigmatizing attitudes predict the desire for social distance: relationship disruption and hygiene, which explain $20 \%$ of the variance.

Conclusions: Combatting stigma in $\mathrm{BD}$ requires a change in behaviors, not just attitudes. We explored the link between stigmatizing attitudes and the desire to interact with affected individuals and found a significant association. The desire to maintain social distance from people with BD was predicted by stigmatizing about regarding their relationships and hygiene habits. By targeting stigmatizing beliefs about relationship disturbances and hygiene in BD, it may be possible to further strengthen anti-stigma initiatives.

\section{Key words}

Bipolar disorder, Stigma, Attitudes, Social distance

\section{Introduction}

Psychiatric stigma is a social prejudice made up of stereotypical negative attitudes toward people living with a mental illness ${ }^{[1]}$. For example, many people believe that individuals who have a mental illness are typically unpredictable, violent, or unreliable. The illness may even be seen as a sign of personal deficits, weakness, deviance, low intelligence, or 
incompetence. With stigmatizing attitudes come discriminatory behaviors that marginalize those affected. Unfortunately, stigma is pervasive in society; it is found among the public as a whole, in the healthcare sector, among friends and family members of those with a mental illness, and is even internalized by the affected individuals themselves ${ }^{[2]}$.

Bipolar disorder (BD) is a highly stigmatized mental illness, as much so as conditions like schizophrenia ${ }^{[3]}$. According to people living with BD and their family members, stigma has serious negative impacts on their social lives, family relationships and occupational achievement. When individuals with BD have high levels of perceived stigma, they tend to experience more severe affective symptoms and greater functional impairment. The negative impact of stigma also affects the family members who support them. The perception of stigma leads to concealment of the illness, withdrawal from social circles and symptoms of social anxiety. This, in turn, is associated with weakened social support networks. However, the impact of stigma goes beyond social support, also affecting the psychiatric treatment that can help them manage the condition; individuals with mental illness and a high sense of stigma are both less inclined to seek professional help ${ }^{[4]}$ and less likely to adhere to treatment ${ }^{[5]}$. Given the complex interplay between stigma, functioning, treatment seeking and disease management, stigma is a key construct in BD that should be further explored to better understand how it works and, ultimately, reduce its impacts.

A variety of approaches have been undertaken in the fight against stigma. These include individual approaches ranging from counseling and cognitive-behavioral therapy to advocacy to self-help ${ }^{[6]}$. Organizational and community-level initiatives include training programs, policies, and protest. Social contact with people with mental illness is a major component of anti-stigma interventions, based on the proposition by intergroup contact theory that direct contact with affected individuals is one of the keys to reducing prejudice ${ }^{[7]}$. Another common target of interventions is to increase knowledge and empathy toward the stigmatized group ${ }^{[8]}$. Contact and education-based approaches have been used to develop interventions to reduce the stigma surrounding bipolar disorder ${ }^{[9,10]}$.

Despite valiant efforts to raise awareness of mental illness and reduce stigma, success has been limited ${ }^{[11]}$. In fact, during the last half of the $20^{\text {th }}$ century, when the scientific understanding of mental illness increased dramatically, stigmatizing beliefs regarding the dangerousness of people with mental illness also increased substantially ${ }^{[12]}$. This highlights the importance of continuing to untangle the complex factors that drive stigma and that determine the success of an anti-stigma initiative. Criticisms of existing approaches to stigma reduction include the notion that increased knowledge or improved attitudes do not necessarily translate directly into reduced discriminatory behavior ${ }^{[11]}$. Based on this premise, operationalizing stigma in terms of behavior and targeting stigmatizing behavior might be more powerful than focusing on stigmatizing attitudes alone.

By assessing the people's willingness or unwillingness to enter into contact with people who have a mental illness, stigma can be tapped from a more behavioral perspective ${ }^{[13]}$. While still not a direct measure of actual behavior, the assessment of the desire for social distance provides an operationalized measure representing behavioral intentions. If stigma reduction interventions can increase the willingness to interact with an individual who has a mental illness, they may be able to directly improve the lives of the people affected. Unfortunately, anti-stigma interventions that have positive impacts on certain aspects of stigma, such as attitudes, awareness and empathy, do not necessarily change peoples' desire to interact with those who have the disorder ${ }^{[14-16]}$.

Since attitudinal messages dominate anti-stigma campaigns, a better understanding of the relationship between stigmatizing attitudes and behavioral intentions is required. By identifying the specific stigmatizing attitudes that are most closely associated with behavioral change, it might be possible to bridge the gap between attitudinal targets and behavioral outcomes. From this perspective, the current study explores the relationship between stigmatizing attitudes and the desire for social distance. The objective is to identify the attitudes that have the greatest impact on the willingness to interact with people who have bipolar disorder, with a view to refining the targets of attitudinal anti-stigma interventions to maximize their impact. 


\section{Method}

\subsection{Participants}

A mixed sample of 94 participants (70 women and 24 men) completed the assessments for the current study. The average age was 42.5 years $(\mathrm{SD}=15.8)$. Of them, 13 participants $(13.8 \%)$ had been diagnosed with BD, $31(33.0 \%)$ were friends or family members of an individual with BD, 22 (23.4\%) were healthcare workers, 17 (18.1\%) were undergraduate nursing students, and $11(11.7 \%)$ were members of the general public. Illustrating the natural overlap between subsamples, $48.7 \%$ of healthcare professionals and students reported contact with a friend or family member who had BD.

\subsection{Procedure}

The current study is an analysis of the baseline data of individuals participating in a research project testing the filmed version of the anti-stigma intervention. Participants provided informed consent, then completed assessments of stigma either online during the week prior to the intervention $(N=52)$ or in pen-and-paper format immediately prior to the intervention $(N=42)$. Overall stigma levels did not differ based on testing procedure. The impact of the intervention as a stigma-reduction tool is reported elsewhere. The study was approved by a hospital-based research ethics board.

\subsection{Measures}

Participants completed a series of validated questionnaires and provided sociodemographic and general background information. The battery of questionnaires included the following:

Mental Illness Stigma Scale (MISS) ${ }^{[17]}$. The MISS is a 28 item questionnaire assessing stigmatizing attitudes toward a single mental illness. The title of the targeted mental illness is entered into the items to customize it to the specific mental illness; for this study, respondents were asked specifically about their attitudes toward BD. The MISS consists of seven subscales: anxiety about contact with people with the mental illness (Anxiety), the belief that mental health professionals are ineffective (Professional Efficacy), that people with the mental illness cannot maintain meaningful relationships (Relationship Disruption), that they have poor grooming habits (Hygiene), that they can be easily identified by appearance (Visibility), that they cannot be treated effectively (Treatability), and that they cannot recover from a mental illness (Recovery). Level of agreement with the statements is indicated on a 7 point Likert scale. For the total score and each subscale, a higher score indicates a more highly stigmatizing attitude. The MISS has been validated, demonstrating good internal consistency and a strong factor structure, as well as the ability to identify high levels of stigmatizing attitudes toward schizophrenia.

Social Distance Scale ${ }^{[13]}$. To measure the respondents' willingness to interact with people who have bipolar disorder, we used the Social Distance Scale. The desire for social distance is assessed by asking participants how willing they would be, on a 5 point Likert scale, to move next door to a person with $\mathrm{BD}$, spend an evening socializing with a person who has the disorder, make friends with the person, start working closely with the person, and have the person marry into the family. A mean score is calculated, with a score of 1 indicating the desire to maintain social distance and a score of 5 indicating high acceptance of social contact, such that a low score indicates a desire for social distance. From the data used in the current study, the SDS shows high internal consistency (Cronbach's $\alpha=.91$ ) and a unifactoral structure.

Knowledge about bipolar disorder. In the absence of knowledge questionnaires adapted to the targeted samples and disorder, participants were asked to provide subjective ratings of their knowledge about BD. They did so using a three-point self-assessment, ranging from minimal (low score) to high knowledge (high score). They also provided similar three-point rankings of the quantity of training they had had in BD to provide some validation of subjective assessments (reading, courses; each evaluated at $0,1-2$, or $3+$ ). Since subjective was knowledge significantly correlated with quantity-of-training rankings $(r=.54)$, subjective knowledge was retained as an estimate of participants' level of knowledge about $\mathrm{BD}$, a higher score indicating more knowledge. 


\subsection{Data analysis}

During data screening as a prerequisite to analyses, one multivariate outlier was identified. Since close inspection revealed a response pattern indicating a misunderstanding of the directionality of scores, this participant's responses were removed from the analyses.

Using data from the remaining 93 participants, Pearson product-moment correlations were calculated to explore the bivariate correlations between MISS attitudinal stigma scores and the desire for social distance. Non-parametric Kruskal-Wallis tests were used to explore categorical knowledge variables. A hierarchical stepwise multiple regression analysis was then conducted to identify the stigmatizing attitudes that predict the desire for social distance. In the first step of the hierarchical regression, age, sex, knowledge about BD, and group membership (patient, friend/family, healthcare worker, nursing student, general public) were entered for the purposes of statistical control. In the second step, the seven categories of stigmatizing attitudes assessed by the MISS were entered using a stepwise procedure. Statistical analyses were conducted using SPSS 13, with $\alpha=.05$ to establish significance. The sensitivity of the regression analyses was calculated with $\mathrm{G}^{*}$ Power 3 power analysis software ${ }^{[18]}$. With seven attitudinal predictors, power of .80 and a significance criterion of .05 , a sample size of 93 is sufficient to detect a medium effect size of $f^{2}=.17$.

\section{Results}

Descriptive statistics describing participants' stigma levels are presented in Table 1. Pearson product-moment correlations were calculated to explore bivariate associations between stigmatizing attitudes and the desire for social distance (see Table 2). Results confirm that individuals who have higher stigmatizing attitudes as a whole (MISS total mean score) have more desire to maintain social distance from individuals with $\mathrm{BD}(r=-.41)$. In addition, four of seven MISS subscales are significantly correlated with the desire for social distance. The strongest effect is for the belief that BD is associated with disrupted relationships. A similar relationship was found for stigmatizing attitudes regarding the treatability of the disorder, anxiety surrounding the disorder, and the hygiene of individuals who have it.

Table 1. Descriptive statistics

\begin{tabular}{lll}
\hline & $\boldsymbol{M}$ & $\boldsymbol{S D}$ \\
\hline Social Distance Scale & 3.72 & .78 \\
DMISS & & .99 \\
Treatability & 2.27 & 1.17 \\
Relationship Disruption & 2.95 & 1.16 \\
Hygiene & 2.32 & 1.14 \\
Anxiety & 2.42 & 1.14 \\
Visibility & 3.54 & 1.44 \\
Recovery & 3.38 & 1.31 \\
Professional Efficacy & 2.67 & .71 \\
Total Average & 2.75 & \\
\hline
\end{tabular}

Since one of the goals of stigma-reduction initiatives is to increase knowledge about BD in order to reduce stigma, the relationship between stigmatizing attitudes and participants' subjective knowledge was explored (see Table 3). Non-parametric Kruskal-Wallis tests were used to compare the stigma scores of participants who rated their knowledge about BD as low, medium, or high. High knowledge was associated with significantly more positive behavioral intentions regarding social distance $\left(\chi^{2}[2]=11.29, p=.004\right)$. Four categories of stigmatizing attitudes also differed by knowledge level: higher knowledge about BD was associated with significantly less anxiety regarding the condition $\left(\chi^{2}[2]=17.26, p\right.$ $<.001)$, better attitudes about recovery $\left(\chi^{2}[2]=8.82, p=.012\right)$, and a more positive view of treatability $\left(\chi^{2}[2]=7.59, p\right.$ $=.023)$, but a stronger belief that the disorder is visible and easily detected $\left(\chi^{2}[2]=10.33, p=.006\right)$. 
Table 2. Correlations between categories of stigmatizing attitudes and the desire for social distance

\begin{tabular}{|c|c|c|c|c|c|c|c|c|}
\hline & 1 & 2 & 3 & 4 & 5 & 6 & 7 & 8 \\
\hline 1. SDS & - & & & & & & & \\
\hline 2. Treatability & $-.30 * *$ & - & & & & & & \\
\hline $\begin{array}{l}\text { 3.Relationship } \\
\text { Disruption }\end{array}$ & $-.38 * *$ & $.34 * *$ & - & & & & & \\
\hline 4. Hygiene & $-.35 * *$ & $.28 *$ & $.41 * *$ & - & & & & \\
\hline 5. Anxiety & $-.35 * *$ & $.34 * *$ & $.65 * *$ & $.24^{*}$ & - & & & \\
\hline 6. Visibility & -.004 & -.12 & .13 & .17 & -.11 & - & & \\
\hline 7. Recovery & -.03 & $.27 *$ & $.30 * *$ & .05 & $.24^{*}$ & -.14 & - & \\
\hline $\begin{array}{l}\text { 8. Professional } \\
\text { Efficacy }\end{array}$ & -.03 & $.56^{* *}$ & .15 & .19 & .10 & .05 & $.22 *$ & - \\
\hline
\end{tabular}

Table 3. Differences in stigma scales based on participants' subjective knowledge about bipolar disorder

\begin{tabular}{lllllll}
\hline & & $\begin{array}{l}\text { Low } \\
\text { Knowledge } \\
(\boldsymbol{N}=\mathbf{3 9 )}\end{array}$ & $\begin{array}{l}\text { Moderate } \\
\text { Knowledge } \\
(\boldsymbol{N}=\mathbf{4 1})\end{array}$ & $\begin{array}{l}\text { High Knowledge } \\
(\boldsymbol{N}=\mathbf{1 3})\end{array}$ & $\boldsymbol{\chi}^{2}(\mathbf{2})$ & $\boldsymbol{p}$ \\
& $\boldsymbol{M}(\boldsymbol{S D})$ & $\boldsymbol{M}(\boldsymbol{S D})$ & & \\
\hline MISS $)$ & & & & & \\
& & $2.55(0.91)$ & $2.11(1.03)$ & $1.95(0.91)$ & 7.59 & $\mathbf{. 0 2}$ \\
& Treatability & $2.69(1.05)$ & $2.92(1.11)$ & 4.17 & .12 \\
& Relationship Disruption & $3.24(1.26)$ & $2.13(1.12)$ & $2.31(1.28)$ & 2.93 & .23 \\
& Hygiene & $2.51(1.17)$ & $1.98(0.84)$ & $2.11(0.90)$ & 17.25 & $<.001$ \\
& Anxiety & $3.00(1.25)$ & $3.59(1.15)$ & $4.38(0.94)$ & 10.33 & $\mathbf{. 0 1}$ \\
& Visibility & $3.22(1.06)$ & $3.21(1.56)$ & $2.73(1.55)$ & 8.82 & $\mathbf{. 0 1}$ \\
& Recovery & $3.77(1.17)$ & $2.56(1.32)$ & $3.35(1.66)$ & 2.42 & .30 \\
& Professional Efficacy & $2.56(1.11)$ & $3.84(0.76)$ & $4.22(0.62)$ & 11.29 & $\mathbf{. 0 0 4}$ \\
\hline
\end{tabular}

To identify the stigmatizing attitudes that uniquely predict the desire for social distance, hierarchical stepwise multiple regression analysis was conducted. The results of the final model, controlling for sociodemographic, group and knowledge variables, are presented in Table 4. After a significant prediction afforded by the control variables entered in the first step of the analyses (age, sex, knowledge, group membership), two MISS subscales significantly predict the desire for social distance: relationship disturbance $(\beta=-.29)$ and hygiene $(\beta=-.28)$. These two predictors explain $20 \%$ of the variance of the desire for social distance above and beyond the $15 \%$ afforded by control variables. Despite several bivariate correlations with SDS scores, the remaining stigmatizing attitudes are not unique predictors of the desire for social distance.

Table 4. Stepwise multiple regression analysis of predictors of the desire for social distance, controlling for knowledge, group membership, age, and sex

\begin{tabular}{llllll}
\hline & $\boldsymbol{B}$ & $\boldsymbol{S E} \boldsymbol{B}$ & $\boldsymbol{\beta}$ & $\boldsymbol{t}$ & $\boldsymbol{p}$ \\
\hline Relationship Disruption & -.196 & .066 & -.292 & -2.978 & .004 \\
Hygiene & -.185 & .067 & -.275 & -2.772 & .007 \\
Knowledge & .261 & .102 & .232 & 2.556 & .012 \\
Age & .011 & .006 & .216 & 1.868 & .07 \\
Group & -.053 & .054 & -.111 & -.982 & .33 \\
Sex & -.094 & .163 & -.052 & -.573 & .57 \\
& & & $R^{2}=$ & .35 & \\
& & & Adj. $R^{2}=$ & .30 & \\
& & & $R=$ & .59 & \\
\hline
\end{tabular}




\section{Discussion}

Results show that stigmatizing attitudes do predict behavioral intentions. However, all attitudes are not equal. Concerns that individuals with bipolar disorder cannot have strong relationships and that they have poor hygiene habits were the unique predictors of the desire for social distance, the strongest weight in the prediction being for relationship disruptions. Based on these results, relationship disruption and hygiene are strong candidate attitudinal variables for anti-stigma campaigns aiming to reduce behavioral manifestations of stigma.

Stigma and relationships are obviously closely intertwined. The stigma surrounding BD clearly erodes the social lives of individuals affected, leaving them feeling isolated and lacking in social support ${ }^{[3]}$. Since a lack of social support is associated with depressive relapse and slower recovery in $\mathrm{BD}^{[19-21]}$, stigma fuels the illness and interferes with a positive outcome by robbing individuals of the social support they need. Stigma reduction, then, would appear to one of the solutions to helping patients develop strong support networks and benefit from the protective properties that social support can offer.

The current study further endorses the importance of social relationships as a component of stigma, but from a different perspective. Since one of the key contributors to a behavioral manifestation of stigma, i.e., the desire for social distance, is the belief that individals with BD cannot maintain strong relationships, the ability of people with BD to maintain strong social relationships would appear to be a key target for anti-stigma interventions. By sending the message that individuals with $\mathrm{BD}$ can have strong relationships, it may be possible to reduce the concerns surrounding relationship disruption that appear to discourage people from entering into contact with affected individuals.

Unfortunately, the stigma-relationship connection is not quite so simple. There is ample evidence in the literature that people with BD do have impaired social functioning, not only during episodes, but also during the euthymic period ${ }^{[22]}$. This extends beyond a simply quantitative lack of social support fueled by stigma. Samples of patients with BD show broad-based impaired social functioning ${ }^{[23]}$, including impaired social competence ${ }^{[24]}$, social cognition ${ }^{[25]}$, and functioning in interpersonal relationships ${ }^{[26]}$. The symptoms experienced during episodic or sub-threshold periods also have an impact on social behaviors. Disturbances such as affect dysregulation and intense reactions to criticism, even during euthymia, are additional pieces to the BD-relationship puzzle ${ }^{[27,28]}$. This is in line with the schizophrenia research, which has suggested that the desire for social distance is associated with a lack of social skills on the part of affected individuals ${ }^{[29]}$.

Since the stigmatizing desire for social distance from individuals with BD is fueled by a fear of impaired interpersonal relationships, and since interpersonal relationships do in fact tend to be impaired to some degree among many people with $\mathrm{BD}$, the solution cannot be as simple as sending out a pro-social message. While the belief that relationships are disrupted can and has been significantly reduced using the anti-stigma initiative associated with this project ${ }^{[30,31]}$, simply sending out a pro-social message while ignoring the social impairment that fuels the desire for social distance would be expected to be of limited benefit over the long term unless it accompanies concrete solutions to address social challenges. The solution, then, must be one that impacts all levels of this complex, vicious cycle of symptoms, social dysfunction, stigmatizing beliefs, and social avoidance. A reduction of stigma surrounding BD appears, then, to require a clinical focus on helping patients achieve not only symptomatic recovery, but also social reintegration ${ }^{[22]}$. This implies not only pharmacological and psychological interventions focusing on mood stability and problem resolution skills, but also community services that provide patients with informal support and empowerment as they rebuild their lives.

This vision is consistent with the recovery model of mental illness, which views recovery as a dynamic process that touches many domains of life, including the social sphere ${ }^{[32]}$. This view calls for a variety of sustained services that empower individuals and support them on their journey to wellness and recovery. This journey extends beyond clinical care and medical treatments to include personal growth, social functioning, autonomy, self-determination, hope, empowerment and support from people the individual can rely on ${ }^{[32-34]}$. By advancing the recovery model, with its 
"journey" metaphor - both in the community to provide patients with multifaceted services to promote social recovery and in anti-stigma work to promote the universality of personal growth and development-it may be possible to build bridges and gradually temper the symptoms-functioning-stigma cycle.

In the current study, beliefs that people with $\mathrm{BD}$ have poor hygiene also predicted the desire for social distance. Like relationship disruption, stigmatizing attitudes regarding $\mathrm{BD}$ and hygiene appear to be elevated to a similar degree as schizophrenia ${ }^{[17]}$. Although acute symptoms can affect self-care behaviors, the relationship between BD and self-care deficits appears to be of a much smaller magnitude than social concerns and to affect only a small minority of individuals with $\mathrm{BD}^{[35,36]}$. Hygiene, then, would be a relevant unique target of anti-stigma interventions, with a goal of reducing this stigmatizing belief as a barrier to social interaction with individuals affected by BD. As confirmed in the current study, interventions to increase knowledge should also continue to be pursued as part of anti-stigma campaigns.

This study does have a number of limitations that should be kept in mind when interpreting the results. First, small sample sizes did not permit the comparison of impacts among different participant groups. However, it should be noted that the samples are not mutually exclusive. For example, people with BD may also have friends/family members with the disorder or work in healthcare professions, while healthcare workers can have the disorder or have friends/family members who do. Nevertheless, the potential differences between broad categories of subsamples should be examined in future studies. In addition, since the Social Distance Scale measures behavioral intentions, but not actual behavior, the results might not accurately reflect the decisions individuals make when faced with possibility of interacting with someone with BD. Lastly, social desirability is always a concern when assessing constructs such as stigma and may have impacted the conclusions drawn.

In sum, this study demonstrates that concerns regarding the disruption of social relationships and the hygiene of individuals with $\mathrm{BD}$ are uniquely associated with the desire for social distance. Given the real impacts that the condition has on social functioning, efforts to reduce stigma must go hand in hand with concerted community efforts to help patients attain social recovery. This might be achieved by applying the recovery model of mental illness to both patient recovery and anti-stigma efforts, with its multidimensional vision that goes beyond symptoms to incorporate the social spheres of life.

\section{References}

[1] Corrigan PW, Roe D, Tsang HWH. Challenging the stigma of mental illness. Hoboken, NJ, US: John Wiley and Sons; 2011. http://dx.doi.org/10.1002/9780470977507

[2] Sartorius N, Gaebel W, Cleveland HR, Stuart H, Akiyama T, Arboleda-Florez J, et al. WPA guidance on how to combat stigmatization of psychiatry and psychiatrists. World Psychiatry. 2010; 9: 131-44. PMid:20975855

[3] Hawke, L.D., S.V. Parikh, and E.E. Michalak, Stigma and bipolar disorder: A review of the literature. Journal of Affective Disorders. 2013; 150(2): 181-91. PMid:23759420 http://dx.doi.org/10.1016/j.jad.2013.05.030

[4] Yap MBH, Wright A, Jorm AF. The influence of stigma on young people's help-seeking intentions and beliefs about the helpfulness of various sources of help. Soc. Psychiatry Psychiatr. Epidemiol. 2011; 46: 1257-65. http://dx.doi.org/10.1111/j.1369-7625.2009.00541.x

[5] Fung KMT, Tsang HWH, Corrigan PW. Self-stigma of people with schizophrenia as predictor of their adherence to psychosocial treatment. Psychiatric Rehabilitation Journal. 2008; 32: 95-104. PMid:18840563 http://dx.doi.org/10.2975/32.2.2008.95.104

[6] Heijnders M, Van der Meij S. The fight against stigma: An overview of stigma reduction strategies and interventions. Psychology, Health \& Medicine. 2006; 11: 353-63. PMid:17130071 http://dx.doi.org/10.1080/13548500600595327

[7] Pettigrew TF, Tropp LR. A meta-analytic test of intergroup contact theory. J. Pers. Soc. Psychol. 2006; 90: 751-83. PMid:16737372 http://dx.doi.org/10.1037/0022-3514.90.5.751

[8] Dalky HF. Mental illness stigma reduction interventions: Review of intervention trials. West. J. Nurs. Res. 2012 ; 34 : 520-47. PMid:21389251 http://dx.doi.org/10.1177/0193945911400638

[9] Rüsch LC, Kanter JW, Angelone AF, Ridley RC. The impact of In Our Own Voice on stigma. American Journal of Psychiatric Rehabilitation. 2008; 11: 373-89. http://dx.doi.org/10.1080/15487760802397660

[10] Parikh S, Michalak EE, Livingston JD, Maxwell V. Reducing stigma: A knowledge translation study of bipolar disorder. Poster presented at the 6th Biennial Conference of the International Society for Affective Disorders, 2012. 
[11] Stuart H, Arboleda-Florez J, Sartorius N. Paradigms lost: Fighting stigma and the lessons learned. New York, NY, US: Oxford University Press; 2012.

[12] Phelan JC, Link BG, Steuve A, Pescosolido BA. Public conceptions of mental illness in 1950 and 1996: What is mental illness and is it to be feared? Journal of Health and Social Behavior. 2000; 41: 188-207. http://dx.doi.org/10.2307/2676305

[13] Link BG, Phelan JC, Bresnahan M, Stueve A, Pescosolido BA. Public conceptions of mental illness: Labels, causes, dangerousness, and social distance. Am. J. Public Health. 1999; 89: 1328-33. PMid:10474548 http://dx.doi.org/10.2105/AJPH.89.9.1328

[14] Livingston JD, Tugwell A, Korf-Uzan K, Cianfrone M, Coniglio C. Evaluation of a campaign to improve awareness and attitudes of young people towards mental health issues. Soc. Psychiatry Psychiatr. Epidemiol. 2012.

[15] Penn DL, Chamberlin C, Mueser KT. The effects of a documentary film about schizophrenia on psychiatric stigma. Schizophr. Bull. 2003; 29: 383-91. PMid:14552511 http://dx.doi.org/10.1093/oxfordjournals.schbul.a007012

[16] Ando S, Clement S, Barley EA, Thornicroft G. The simulation of hallucinations to reduce the stigma of schizophrenia: a systematic review. Schizophr. Res. 2011; 133: 8-16. PMid:22005017 http://dx.doi.org/10.1016/j.schres.2011.09.011

[17] Day EN, Edgren K, Eshleman A. Measuring stigma toward mental illness: Development and application of the Mental Illness Stigma scale. Journal of Applied Social Psychology. 2007; 37: 2191-219. http://dx.doi.org/10.1111/j.1559-1816.2007.00255.x

[18] Faul F, Erdfelder E, Lang A-G, Buchner A. G*Power 3: A flexible statistical power analysis program for the social, behavioral, and biomedical sciences. Behavior Research Methods. 2007; 39: 175-91. PMid:17695343 http://dx.doi.org/10.3758/BF03193146

[19] Cohen AN. The nature and effect of interpersonal relationships on the course of bipolar I disorder, University of California, Los Angeles. 2001, 1071-1071.

[20] Johnson L, Lundström O, Åberg-Wistedt A, Mathé AA. Social support in bipolar disorder: Its revelance to remission and relapse. Bipolar Disorders. 2003; 5(2): 129-37. PMid:12680903 http://dx.doi.org/10.1034/j.1399-5618.2003.00021.x

[21] Johnson SL, Winett CA, Meyer B, Greenhouse WJ, Miller I. Social support and the course of bipolar disorder. J. Abnorm. Psychol. 1999; 108: 558-66. PMid:10609420 http://dx.doi.org/10.1037/0021-843X.108.4.558

[22] Elgie R, Morselli PL. Social functioning in bipolar patients: The perception and perspective of patients, relatives and advocacy organizations--A review. Bipolar Disorders. 2007; 9: 144-57. PMid:17391357 http://dx.doi.org/10.1111/j.1399-5618.2007.00339.x

[23] Dickerson FB, Sommerville J, Origoni AE, Ringel NB, Parente F. Outpatients with schizophrenia and bipolar I disorder: Do they differ in their cognitive and social functioning? Psychiatry Res. 2001; 102: 21-7. http://dx.doi.org/10.1016/S0165-1781(01)00247-5

[24] Depp CA, Mausbach BT, Harvey PD, Bowie CR, Wolyniec PS, Thornquist MH, et al. Social competence and observer - rated social functioning in bipolar disorder. Bipolar Disorders. 2010; 12: 843-50. PMid:21176031 http://dx.doi.org/10.1111/j.1399-5618.2010.00880.x

[25] Samamé C, Martino DJ, Strejilevich SA. Social cognition in euthymic bipolar disorder: Systematic review and meta - analytic approach. Acta Psychiatr. Scand. 2012; 125: 266-80. PMid:22211280 http://dx.doi.org/10.1111/j.1600-0447.2011.01808.x

[26] Rosa AR, Reinares M, Michalak EE, Bonnin CM, Sole B, Franco C, et al. Functional impairment and disability across mood states in bipolar disorder. Value in Health. 2010; 13: 984-8. PMid:20667057 http://dx.doi.org/10.1111/j.1524-4733.2010.00768.x

[27] Cuellar AK, Johnson SL, Ruggero CJ. Affective Reactivity in Response to Criticism in Remitted Bipolar Disorder: A laboratory Analog of Expressed Emotion. J. Clin. Psychol. 2009; 65: 925-41. PMid:19459195 http://dx.doi.org/10.1002/jclp.20596

[28] Leboyer M, Kupfer DJ. Bipolar disorder: New perspectives in health care and prevention. J. Clin. Psychiatry. 2010; 71:1689-95. PMid:21190640 http://dx.doi.org/10.4088/JCP.10m06347yel

[29] Penn DL, Kohlmaier JR, Corrigan PW. Interpersonal factors contributing to the stigma of schizophrenia: Social skills, perceived attractiveness, and symptoms. Schizophr. Res. 2000; 45: 37-45. http://dx.doi.org/10.1016/S0920-9964(99)00213-3

[30] Hawke, L.D., S.V. Parikh, and E.E. Michalak, Reducing stigma toward people with bipolar disorder: Impact of a filmed theatrical intervention based on a personal narrative. International Journal of Social Psychiatry, In press.

[31] Michalak, E.E., et al., Using theatre to address mental illness stigma: a knowledge translation study in bipolar disorder. International Journal of Bipolar Disorder, in press.

[32] Brennaman L, Lobo ML. Recovery from serious mental illness: a concept analysis. Issues Ment. Health Nurs. 2011; 32 : 654-63. PMid:21932928 http://dx.doi.org/10.3109/01612840.2011.588372

[33] Anthony W. Recovery from Mental Illness: The Guiding Vision of the Mental Health Service System in the 1990s. Psychosocial Rehabilitation Journal. 1993; 16: 11-23. http://dx.doi.org/10.1037/h0095655

[34] Torrey WC, Wyzik P. Recovery Vision as a Service Improvement Guide for Community Mental Health Center Providers. Community Ment. Health J. 2000; 36: 209-16. PMid:10800868 http://dx.doi.org/10.1023/A:1001802612944

[35] Hayhurst H, Palmer S, Abbott R, Johnson T, Scott J. Measuring health-related quality of life in bipolar disorder: Relationship of the EuroQol (EQ-5D) to condition-specific measures. Quality of Life Research: An International Journal of Quality of Life Aspects of Treatment, Care \& Rehabilitation. 2006; 15: 1271-80. PMid:16972160 http://dx.doi.org/10.1007/s11136-006-0059-Z

[36] Yatham LN, Lecrubier Y, Fieve RR, Davis KH, Harris SD, Krishnan AA. Quality of life in patients with bipolar I depression: data from 920 patients. Bipolar Disorders. 2004; 6: 379-85. PMid:15383130 http://dx.doi.org/10.1111/j.1399-5618.2004.00134.x 